\title{
Research on the Mobile Reading Interface Design Based on the Smart Phone APP
}

\author{
Shoujin Wang ${ }^{1, a}$, Huanhuan $\mathrm{Jin}^{1, \mathrm{~b}}$ and Molei $\mathrm{Li}^{1, \mathrm{C}^{*}}$ \\ School of Information \& Control engineering, Shenyang Jianzhu University, Shenyang, China \\ a 23917240@qq.com, b2429222877@qq.com, c854133055@qq.com \\ * The corresponding author
}

Keywords: Mobile reading; Interface design; Smart phone APP

\begin{abstract}
The paper analyzes the market profile, the scale and trend of modern mobile reading and points out that in the field of mobile reading which based on the smart phone APP has a quite important significance in the era of 'Internet + '. And through the deep analysis of the content driven mobile reading APP, the paper explores the interface design of mobile reading APP path from personal space interface and reading interface, and also gives feasible suggestions from the perspective of the interaction, content and aesthetic experience to make it more in line with users' aesthetic experience and expectations in terms of artistry, practicality and professionalism.
\end{abstract}

\section{Introduction}

With the continuous development of the 'Internet + ' technology, mobile reading is gaining more and more popularity with its obvious advantages of convenience, timeliness, cheap price and easy access. Whether in the subway, the bus and other means of transportation, or coffee shop, waiting room (airport) and other rest spaces, "phubbers" are almost everywhere. At the same time, traditional paper-based reading has been greatly impacted and even could be replaced.

The portability and privacy of mobile phones not only meet people's demand for reading anytime and anywhere, but gradually change people's reading habits. With the change of reading media and reading methods, new demands have also emerged[1]. They are not only reflected in the extension of bookmarks, notes, comments, sharing and other related functions of mobile reading APP, but include the interaction and aesthetics of its page design.

Content driven APP as a mainstream of mobile reading APP right now, not only can realize sharing, collecting and reading of high quality content of basic operations, also can also develop functions according to different preferences of the audience. This paper explores the interface design path of content mobile reading APP from three aspects of personal space interface, and reading interface.

\section{Market Profile of Mobile Reading in China}

According to the data of the 14th national reading survey, Chinese adult citizens read 7.86 books per capita in 2016, of which 4.65 are printed books and 3.21 are e-books[2]. In 2016, the comprehensive reading rate of all media in China's adult citizens was $79.9 \%$, and the contact rate of digital reading mode was $68.2 \%$.It was up 4.2 percentage points from $64 \%$ in 2015 and has been rising for eight consecutive years[3]. 50.2 percent of people were able to receive the for downloads of e-books, and the acceptable price is increasing year by year.

Meanwhile, for the first time since 2014, Chinese digital reading rate has surpassed that of books, within it mobile reading became the main growth point. With the rapid development of the mobile Internet, the mobile reading market is experiencing a spurt of growth[4]. Taking the data of 20142016 as the reference value, we can get the general situation of scale machine profitability in the mobile reading market, as shown in Table 1. 
Table 1 2014-2016 Chinese mobile reading market size basic overview

\begin{tabular}{|c|c|c|c|c|}
\hline \multirow{2}{*}{ Year } & $\begin{array}{c}\text { Mobile Internet } \\
\text { market revenue } \\
\text { [hundred million } \\
\text { yuan]/growth }\end{array}$ & $\begin{array}{c}\text { Mobile reading } \\
\text { revenue[hundred } \\
\text { million } \\
\text { yuan]/growth }\end{array}$ & $\begin{array}{c}\text { Mobile reading } \\
\text { active users } \\
\text { [hundred million } \\
\text { people]/growth }\end{array}$ & $\begin{array}{c}\text { The age of users' } \\
\text { group/the age of } \\
\text { paying users' age }\end{array}$ \\
\cline { 1 - 4 } 2014 & $13437.7 / 183.8 \%$ & $88.4 / 41.4 \%$ & $5.9 / 20.9 \%$ & \multirow{2}{*}{$20-39 / 26-30$} \\
\cline { 1 - 3 } 2015 & $30794.6 / 129.2 \%$ & $108 / 22.2 \%$ & $6.5 / 10.2 \%$ & \\
\cline { 1 - 3 } 2016 & $46720.6 / 51.7 \%$ & $130.3 / 20.6 \%$ & $6.9 / 6.2 \%$ & \\
\hline
\end{tabular}

Data source: Analysis YiGuanZhiKu; Sutu research institute

The above data shows that: firstly, the mobile reading market is growing rapidly, which indicates that people's reading mode has changed significantly, and mobile reading mode has gradually become the mainstream with great market potential[5]. Secondly, the revenue of mobile reading market accounts for a low proportion of the entire Internet market revenue, which has a large profit margin. It is urgent to develop a new profit model. Thirdly, the growth rate of active users of mobile reading is slowing down after the continuous increase of the number of active users, and the speed of new users is slowing down. Besides developing new users, the retention and value mining of old users should be strengthened[6]. Fourthly, most of the users of mobile reading are young users, who have developed the habit of consuming on the mobile end, and have great potential to pay and strong ability to pay. Fifthly, the age of mobile reading users has changed a bit compared with previous years, with more than 70\% of people aged 20-39[7]. the forecast of Chinese mobile reading market see Fig. 1.

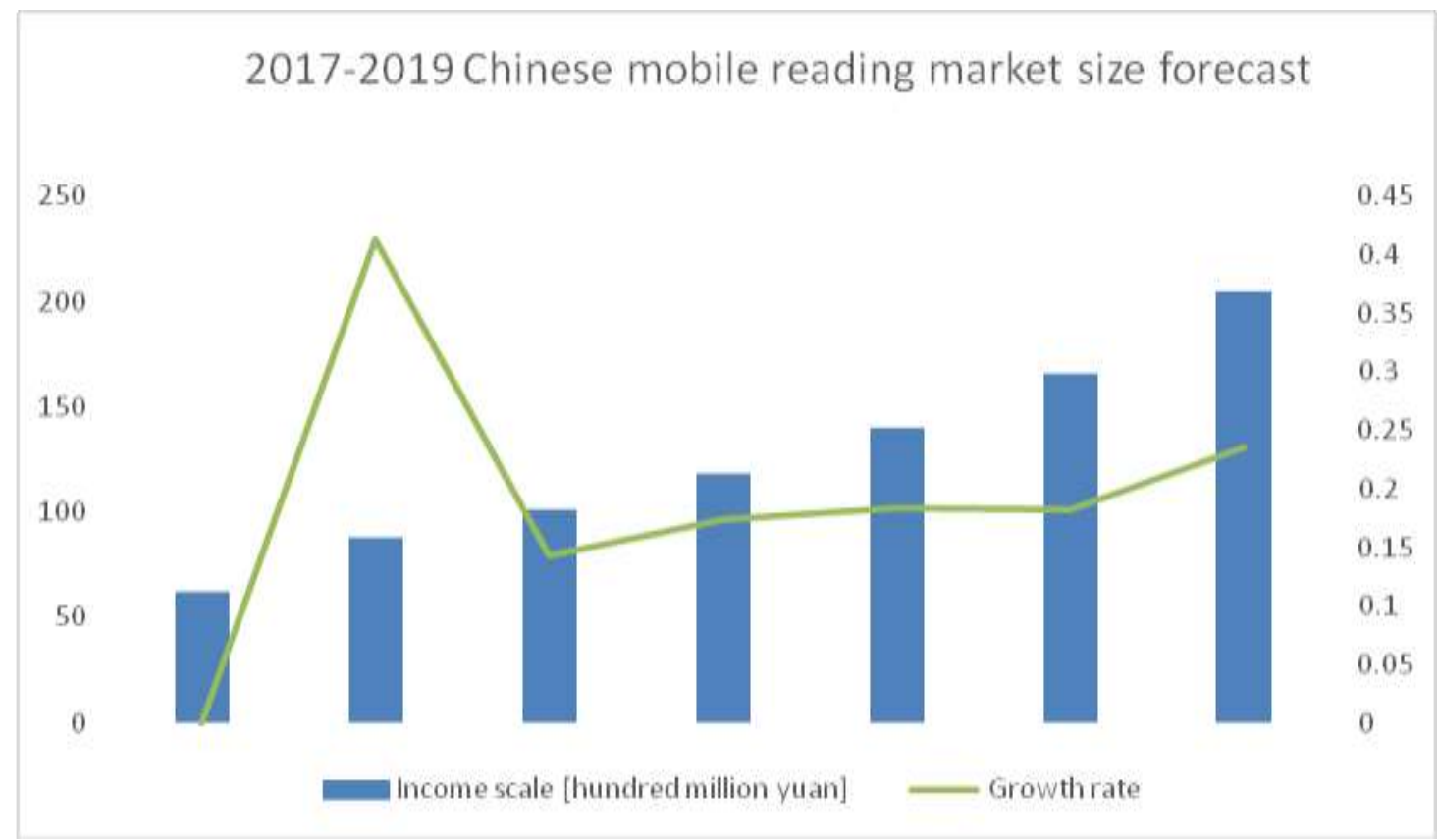

Figure 1. Finite 2017-2019 Chinese mobile reading market size forecast

\section{Analysis on Interface Design Requirements of Smart phone e-reading APP}

In the era of rapid development of 'Internet +', reading areas are more vulnerable to be shocked from other fields, so the function of e-reading app and the design of the interface must constantly innovate to satisfy customers' diversified needs. The author conducts an in-depth investigation and research on the reading habits and demands of mainstream users of mobile reading app, and analyzes them from the following two points: 
Personal Space Interface Requirements. In the time of the pursuit of personality and aesthetics, personal space as an important sector in the mobile reading app, not only can satisfy each users' personalization and can inject vitality into the interface design of the whole APP. In the traditional paper reading, users won't be able to meet their individual needs through reading, but in the era of mobile reading, personalized private space design has already occupied a considerable proportion in the same kind of market competition. To users, in introduction to ensure the interface is clear, simple ,controllable, the theme' clear-cut, and the natural interface transition, attention should also be paid to differentiating between the consistency within the plate and the appearance of different layers in the interaction process, while ensuring that the page has a strong and natural sense of visual hierarchy. The design case one see Fig. 2.

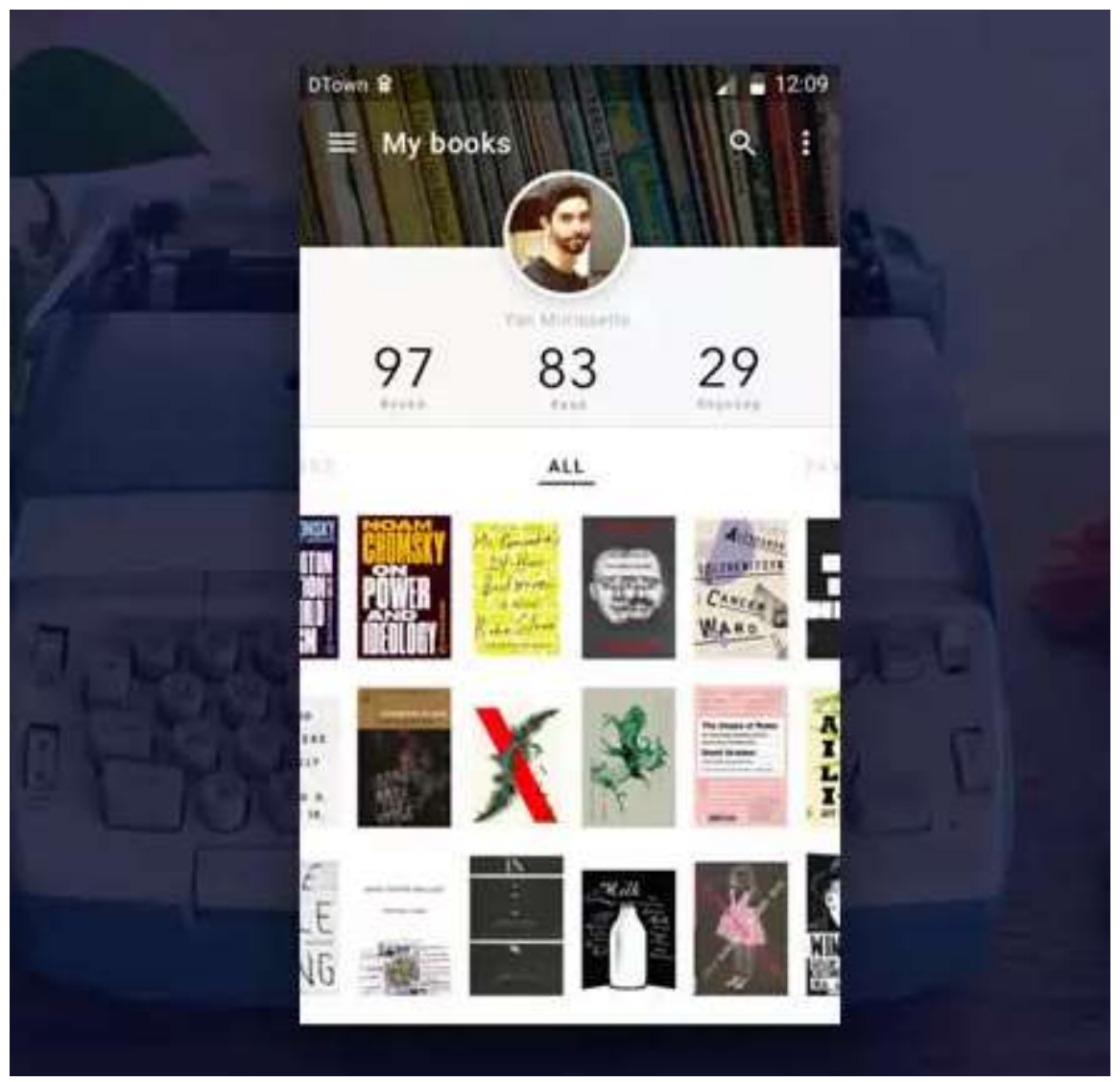

Figure 2. Finite Design case one

Reading Interface Requirements. For mobile reading APPs, how to make the users feel more comfortable during their reading is the main core of the users' experience, so the reading interface is extremely important to the whole design, it should satisfy the following points in main:

Clear and Definite Forms of Expression. To ensure the user can access to information easily and conveniently in the reading process, the interface design must ensure that the sharpness of form expression. It should not only consider the matching problem of resolution, but the background and font colors that are involved in the reading should be carefully matched. Meanwhile, it has to try guarantee the specialization of layout (the automatically adaptive adjustment of the font size on the screen, day and night mode automatically adaptive switch), personalization( font size, line spacing, and the adjustment of the background) and purity (avoid the advertising and other miscellaneous information in the reading interface)

Coordination Between Text and Pictures. In mobile reading, visual perception is actually important. At present, most content driven APPs adopt the form of "multiple pictures + text" to ensure a better visual experience for users, but ignore the problem that more photos can also bring about confusion and tedious of the interface. Since it's a form of mobile reading, we should try our 
best to keep the reading interface much more simple. Considering the above situation, "single picture + text" is a better choice. The design case two see Fig. 3.

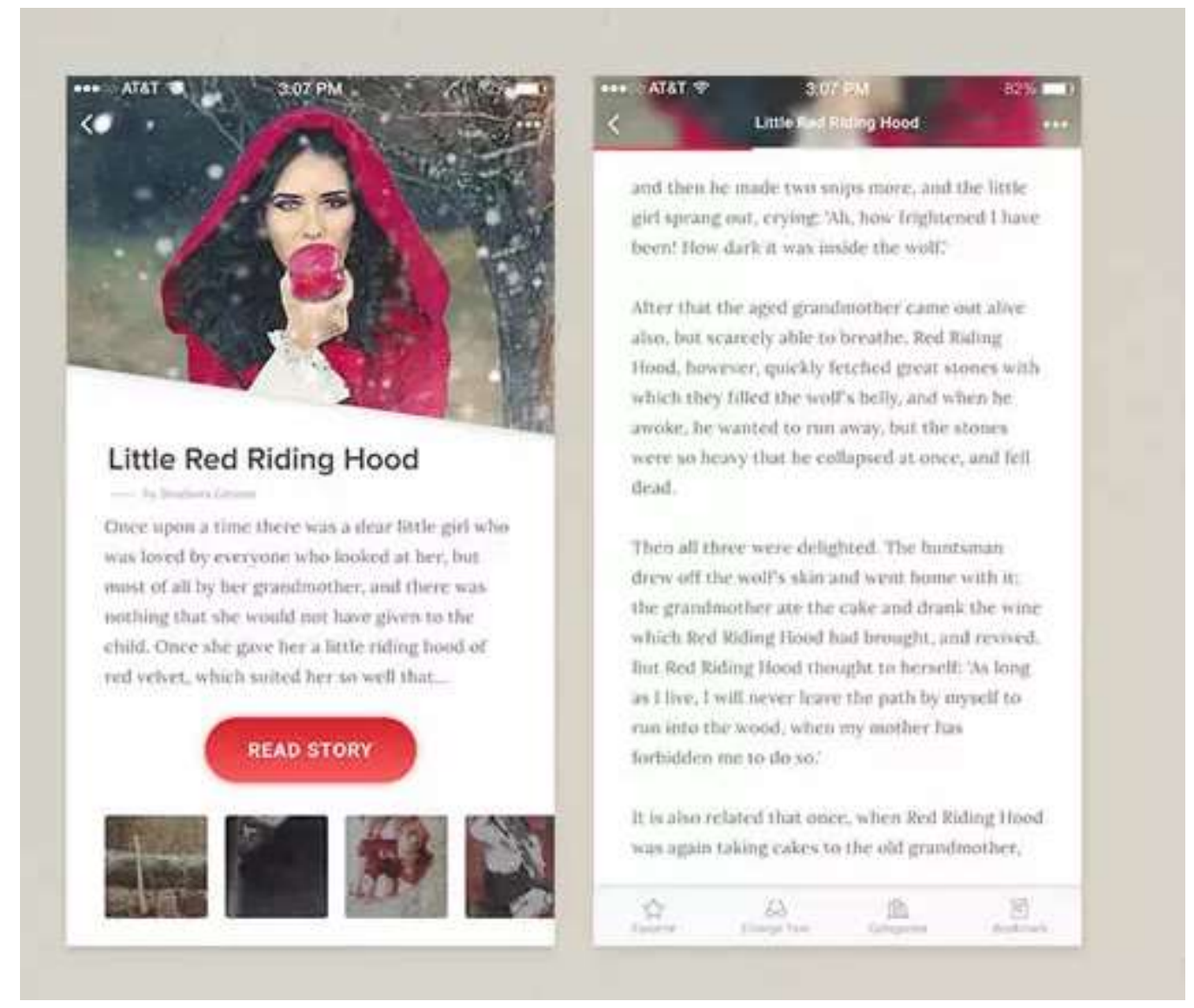

Figure 3. Finite Design case two

Facilitate the Communication Between Readers and Writers. In the paper reading era, it is difficult for us to establish contact with the author of the book, but under the background o8f mobile reading, we have to build platform to shorten the jet lag of communication between readers and the author as much as possible, which needs to introduce the "mini card" of the author at the top of the reading interface, making it much easier for reader enter the author's personal space quickly, and to see more works, concern, or direct messages about the author. It also should introduce small buttons ,such as 'like' and 'collection' in the reading interface to convenient the readers enriching their personal reading content through the use of APP.

\section{Suggestions on the Feasibility of Improving the Interface Design of Smart-phone Mobile Reading APP.}

Raise the Publication "Threshold" by Applying for Certification. For content driven mobile reading APPs, the quality of the content is crucial. How to retain the old users and encourage them to publish original, and attract more new high-quality user at the same time, thus to control the quality of the users group initiatively is question that every product manager for content driven APPs should ponder. Many current driven APPs are in the 'out of control' situation, not just the mobile reading field, that situation leading the product development a large deviation from the original design purpose, such as content driven video APP, kuaishou, even has attracted a large number of users in the process of marketing, but it was soon taken in the wrong direction by parts of low-quality users. Following that was a frenzy of negative news. Also given priority to content, mobile reading APPs should be in alignment with the user segment, attach great importance to the user's published "threshold", and dare to jump out of the constraint of 'masses' APPs, take the 
initiative to raise the threshold, to control the content quality at source and provide users with a better reading environment.

Introduce Diversified Bookmarking Forms. Diversified bookmark forms can not only enhance the professionalism and enjoyment of APP reading, but also improve the user's participation in APP. In general, traditional mobile reading apps often use underscore and color mark to establish text labels on the setting of bookmarks, which is not conducive to users' more efficient recording of their reading experience. In addition, with the development of artificial intelligence in recent years, the integration of voice tags into mobile reading has become an emerging trend that cannot be ignored. By making voice bookmarks with shortcut button, you can quickly capture the inspiration of each user, and on the basis of artificial intelligence, you can also convert voice input into text bookmarks.

Introduce the Function of "not Interested". To ensure the vitality and vigor, a mobile reading APP needs to constantly meet the personalized requirements of users, Simply recommending hot content is no longer enough to tap into the deep reading needs of core users, so in this case you can rely on big data and cloud computing power to push the personal hot content for the users by introducing "not interested" function. By giving the choice of reading to the users, APP can easily find the correct reading style more efficiently according to users' reading habits, so as to serve users better.

\section{Conclusions}

Driven by the integration of culture and technology in today's world, paper-based reading is gradually replaced by diversified mobile reading. Under the guidance of huge demand, there are huge opportunities whether in the upstream or downstream of the industry chain of Chinese mobile reading market. However, the early traditional mobile reading apps have become increasingly difficult to meet users' complex functional requirements. Therefore, functional innovation must be carried out on the basis of interface design. At the same time, the hardware and network advantages of intelligent equipment should be made full use of. Taking users' needs as the first priority and introducing more new elements of mobile network on the basis of optimizing users' interface so that users can get a better reading experience, and it's good for making the development of mobile reading health for a long time.

\section{Acknowledgement}

This work was supported by the Liaoning Provincial Social Planning Fund (L15BGL017) and science and technology program of Liaoning(20170540767).

\section{References}

[1] Liu X Z, Ding J P. The Affordance Research on APP Interface Design of Smart Phone[J]. Packaging Engineering, 2017.

[2] Kim H W. A Study on the Context of Affordance in Smart-phone Interface[J]. 2015, 18(5):663670.

[3] Jin Y, Fang X, Wang Y. Research on the Analysis Method of Text Design in Mobile Phone Interface: Centered on the Network of Smart phone[J]. Design Research, 2016.

[4] Feng J W, University N N. Negative Space in the Application Research of Smart-phone APP Icon Design[J]. Art \& Design, 2016.

[5] Ting-Ting W U, Dai B X, University L N. Research on the Design of Mobile Phone app for Older People based on User Requirements Survey[J]. Economic Research Guide, 2016.

[6] Yang M, Huang H. Research on Interaction Design of Intelligent Mobile Phone for the Elderly Based on the User Experience[M]// Human Aspects of IT for the Aged Population. Design for Aging. Springer International Publishing, 2015:528-536.

[7] Dong R. The Study of Smartphone APP Interface Design[C]// International Conference on Computer Sciences and Automation Engineering. 2016. 